\title{
Bi-Enzymatic Conductometric Biosensor for Detection of Heavy Metal Ions and Pesticides in Water Samples Based on Enzymatic Inhibition in Arthrospira platensis
}

\author{
Nadèje Tekaya ${ }^{1,2}$, Olga Saiapina ${ }^{3}$, Hatem Ben Ouada ${ }^{4}$, Florence Lagarde1, \\ Philippe Namour ${ }^{1}$, Hafedh Ben Ouada ${ }^{2}$, Nicole Jaffrezic-Renault ${ }^{1}$ \\ ${ }^{1}$ Institute of Analytical Sciences, University of Lyon, Villeurbanne, France \\ ${ }^{2}$ Laboratory of Interfaces and Advanced Materials, Faculty of Sciences, University of Monastir, \\ Monastir, Tunisia \\ ${ }^{3}$ Institute of Molecular Biology and Genetics of National, Academy of Sciences of Ukraine, Kyiv, Ukraine \\ ${ }^{4}$ National Institute of Marine Sciences and Technologies, University of Monastir, Monastir, Tunisia \\ Email: tekayanadeje@yahoo.fr
}

Received 17 February 2014; revised 19 March 2014; accepted 16 April 2014

Copyright $@ 2014$ by authors and Scientific Research Publishing Inc.

This work is licensed under the Creative Commons Attribution International License (CC BY).

http://creativecommons.org/licenses/by/4.0/

(c) (i) Open Access

\begin{abstract}
An original bi-enzymatic biosensor was designed by immobilizing Arthrospira platensis cells, called Spirulina, on gold interdigitated transducers. Phosphatase and esterase activities were inhibited, respectively, by heavy metals and by pesticides. Inhibition activities were observed with different mixtures of pesticides + heavy metals. The quantification limits for $\mathrm{Cd}^{2+}$ and $\mathrm{Hg}^{2+}$ are $10^{-20} \mathrm{M}$ in mixture and in pure solution. The quantification limits of parathion-methyl, paraoxon-methyl and triazine are respectively $10^{-20} \mathrm{M}, 10^{-18} \mathrm{M}$ and $10^{-20} \mathrm{M}$ in mixture and pure solutions. These results show that there is no synergistic effect between the two families of pollutants. Qualitative contamination of effluent samples and their purification after passing through a municipal wastewater treatment plant were observed by our bi-enzymatic biosensor and confirmed by classical analytical techniques for heavy metal ions.
\end{abstract}

Keywords

Inhibition, Phosphatase Activity, Esterase Activity, Conductometry, Arthrospira platensis

\section{Introduction}

In the open environment, humans and animals placed in the food chain and in particular the marine food chain

How to cite this paper: Tekaya, N., et al. (2014) Bi-Enzymatic Conductometric Biosensor for Detection of Heavy Metal lons and Pesticides in Water Samples Based on Enzymatic Inhibition in Arthrospira platensis. Journal of Environmental Protection, 5, 441-453. http://dx.doi.org/10.4236/jep.2014.55047 
are exposed to heavy metal poisoning due to the ability of these pollutants to concentrate via the food chain. Present in traces, the toxicity of heavy metals becomes a serious threat to human health when they bioaccumulate in micro-organisms, thus inducing biomagnification. Pesticides have been widely used for decades in agriculture, medicine and industries as they are highly efficient as insecticides and herbicides; they are highly neurotoxic and carcinogenic [1] [2].

These harmful effects highlight the need for instituting a rapid systematic and continuous monitoring of pollutants. Electrochemical platform detection [3]-[8] and biosensors are such devices that can be implemented. A lot of works has been done with electrochemical, piezoelectric or optical transducers for the measurement of pesticides through enzyme inhibition [9]-[17]. These biosensors use either cholinesterase (ChE) in conjunction with choline oxidase (ChO) or only AChE [18] [19]. Biosensors for the detection of heavy metals are based on enzyme inhibition of phosphatase activity (PA) and urease [20]-[23]. The majority of these biosensors are based on immobilized pure enzymes. These enzymes cannot be immobilized on the same sensor easily because of their different optimal operational conditions. Arkhypova et al. [21] have proposed a multibiosensor based on enzyme inhibition for pollutant detection. However, they have faced stability problems when immobilizing several enzymes on a multi-detection array. This is why an emerging device for toxic substances monitoring is the enzyme electrode, but it still has limitations related to simplicity of use, stability, portability and cost. Micro-organisms can be a good bioreceptor for multi-detection. Recently, the development of whole-cell biosensors has attracted increasing interest. Microalgae were used in various studies to develop whole-cell biosensors for the control of toxic pollutants in aquatic environments [5]-[7] [24]-[28].

Enzymatic activities, esterase activity (EA) [29] and phosphatase activity [30] are present in the same micro-organism which is Arthropira platensis [29] [30]. Arthropira platensis, called Spirulina, is a Gram negative bacterium. It is also considered as a blue-green microalga. These enzyme activities can be inhibited by two families of pollutants in order to obtain a bi-enzymatic biosensor: phosphatase activity is inhibited by heavy metals and esterase activity is inhibited by pesticides. In this study, the kinetic proprieties of phosphate and esterase activities were directly determined using conductometric transduction.

Many works have been carried out with these conductometric biosensors for the detection of a variety of molecules [31] [32]. This type of biosensor presents many advantages over other types of transducers: it can be produced through inexpensive thin film standard technology, no reference electrode is needed, the transducers are not light sensitive and differential mode measurements allow the cancellation of a lot of interference [22]. Spirulina cells were immobilized on the working electrode of gold interdigitated transducers (IDTs) and on the reference electrode, only BSA was immobilized. Gold nanoparticles were integrated in the immobilization process. Their roles in the amplification of the measured conductance signal have been already demonstrated in [33].

\section{Experimental}

\subsection{Chemical and Biological Reagents}

Disodium p-nitrophenylphosphate (pNPP) and acetylthiocholine chloride (AChCl) purchased from Sigma-Aldrich were used as the substrates for measuring APA and AChE activities respectively. They were dissolved in a buffer solution to prevent a change of the total conductivity of the measuring medium when adding the substrate. Sodium hydrogenophosphate and sodium dihydrogenophosphate were purchased from Sigma-Aldrich. Phosphate buffer was prepared by dilution in Milli-Q water to obtain a concentration of $5 \mathrm{mM}\left(\mathrm{Na}_{2} \mathrm{HPO}_{4}\right.$ and $\mathrm{NaH}_{2} \mathrm{PO}_{4}$ ) and the $\mathrm{pH}$ was fixed at 5.2.

To inhibit APA, the stock solutions of cadmium $\left(\mathrm{Cd}^{2+}\right)$ and mercury $\left(\mathrm{Hg}^{2+}\right)$ were prepared from pure standard solutions purchased from Sigma-Aldrich. And to inhibit AChE, the stock solutions of parathion-methyl, paraoxon-methyl and triazine, were prepared from products purchased from Sigma-Aldrich. Stock solutions were stored at $4^{\circ} \mathrm{C}$ and fresh dilutions were prepared, in $5 \mathrm{mM}$ phosphate buffer, 15 min before each series of measurements.

Monodispersed gold nanoparticles were purchased from Sigma-Aldrich, their mean particle size being $20 \mathrm{~nm}$.

Bovine serum albumin (BSA), glutaraldehyde (GA) (grade II, 25\% aqueous solution) and the polyelectrolyte used in this study, Poly(allylamine Hydrochloride) (PAH) were purchased from Sigma-Aldrich.

Arthrospira platensis (Compere 1968/3786 strain) called Spirulina, was cultivated under sterile conditions in Zarrouk liquid medium containing: (g/L) $\mathrm{NaNO}_{3}, 2.50 ; \mathrm{K}_{2} \mathrm{HPO}_{4}, 0.50$; $\mathrm{NaHCO}_{3}, 10.00 ; \mathrm{NaCl}, 1.00 ; \mathrm{MgSO}_{4} \cdot 7 \mathrm{H}_{2} \mathrm{O}$, 
0.2; $\mathrm{CaCl}_{2} \cdot 2 \mathrm{H}_{2} \mathrm{O}, 0.02 ; \mathrm{FeSO}_{4} \cdot 7 \mathrm{H}_{2} \mathrm{O}, 0.01$. All salts were of analytical grade and were purchased from Acros Organics. The medium was adjusted to $\mathrm{pH} 9.0$ using $\mathrm{NaOH}$ solution. Cultivation was conducted in $5 \mathrm{~L}$ Erlenmeyer flasks. Cultures were maintained at $26^{\circ} \mathrm{C} \pm 1{ }^{\circ} \mathrm{C}$ under air bubbling and continuously exposed to UV lamps $\left(100 \mu \mathrm{mol} \cdot \mathrm{photon} / \mathrm{m}^{2} \cdot \mathrm{s}\right)$. After that, the biomass was recovered by filtration, washed with physiological liquid (9 $\mathrm{g} \cdot \mathrm{L}^{-1} \mathrm{NaCl}$ in UHQ water).to remove the nutrient salts, and then lyophilized. The resulting powder was protected from moisture by storage in a closed vessel at $4^{\circ} \mathrm{C}$. Spirulina was dispersed in $5 \mathrm{mM}$ phosphate buffer and was then placed under ultrasound and filtered $(0.8 \mu \mathrm{m})$ before analysis. As Spirulina is made of transparent cells stacked end-to-end and entrapped with a sheath forming a spiral filament, the sheath was broken through sonication and filtration in order to separate the individual cells. This last step was crucial for our studies based on the enzymatic activities of Spirulina.

\subsection{Scanning Electronic Microscopy}

The SEM images were captured using a Quanta TM 250 microscope (FEI) in degraded pressure mode (i.e. injection of a certain water pressure in the analysis chamber, in order to observe the cells under moist conditions). Cells needed to be pretreated before imaging. They were fixed with covalent links using glutaraldehyde solution $(3 \%, v / v)$ purchased from Sigma-Aldrich, specially purified for use as an electron microscopy fixative. Spirulina-based biosensors were immersed in this solution for $45 \mathrm{~min}$. Then, a series of dehydration steps in successive absolute ethanol solutions was applied for 10 min using increased concentrations $(20 \%, 40 \%, 60 \%$, $80 \%$, and $100 \%$ ethanol).

\subsection{Sensor Design}

The conductometric transducers (Figure 1(a)) were fabricated at the V.Ye. Lashkaryov Institute of Semiconductor Physics (Kyiv, Ukraine). Each of them consisted of two identical pairs of interdigitated thin film electrodes (IDT electrodes) (150 nm thick), fabricated by gold vapor deposition onto a non-conducting pyroceramic substrate $(5 \times 30 \mathrm{~mm})$. The technique of sensor manufacturing has been reported previously [33]-[35]. A $50 \mathrm{~nm}$ thick intermediate $\mathrm{Cr}$ layer was used to improve the adhesion of Au to the substrate. Both the digit width and interdigital distance were $10 \mu \mathrm{m}$, and their length was $\sim 1.5 \mathrm{~mm}$. As a result, the sensitive area of each pair of electrodes was $\sim 2.9 \mathrm{~mm}^{2}$ (Figure 1(a)).

\subsection{Conductometric Device}

A biosensor analyzer consisting of a sensor block and an electronic measuring block (a portable four-channel biosensor analyzer) was developed in collaboration with the Institute of Electrodynamics of the National Academy of Sciences of Ukraine and it was reported by Dzyadevych et al. [35]. The sensor block consisted of a stand with a fixed block of holders; each holder was connected to the fingers of an appropriate conductometric biosensor. An electronic measuring block consisted of the following modules: a secondary transducer and a basic measurement-control module. A personal computer with specific software support was an integral part of the measuring block. Using a generator, a sinusoidal excitation signal with a frequency of $30 \mathrm{kHz}$ and amplitude of $10 \mathrm{mV}$ was applied to the two exciting electrodes. These conditions avoided faradic processes, double-layer charging, and polarization of the microelectrodes. The signals measured were processed using the lock-in amplifier method, i.e. they were filtered using a low bandwidth centered on the excitation frequency and then transmitted to the synchronous detection which provided the difference of conductivity between the working electrode and the reference electrode. In fact, this system transformed the local variations in conductivity to a change of the active conductivity which can be recovered as information at the output of the system, such as variations in the output signal versus time.

Measurements were performed at room temperature in a glass vessel of $4 \mathrm{~mL}$ volume. The biosensor was immersed gently into $5 \mathrm{mM}$ phosphate buffer. A magnetic stirrer ensured solution homogeneity throughout the experiments. After signal stabilization, different quantities of the substrate were added in the measurement vessel. A rinsing step was performed between two successive measurements.

\subsection{Electrochemical Impedance Spectroscopy (EIS) Measurements}

The measurements were performed with an electrochemical impedance analyzer "Voltalab PGZ 402” (Hach- 


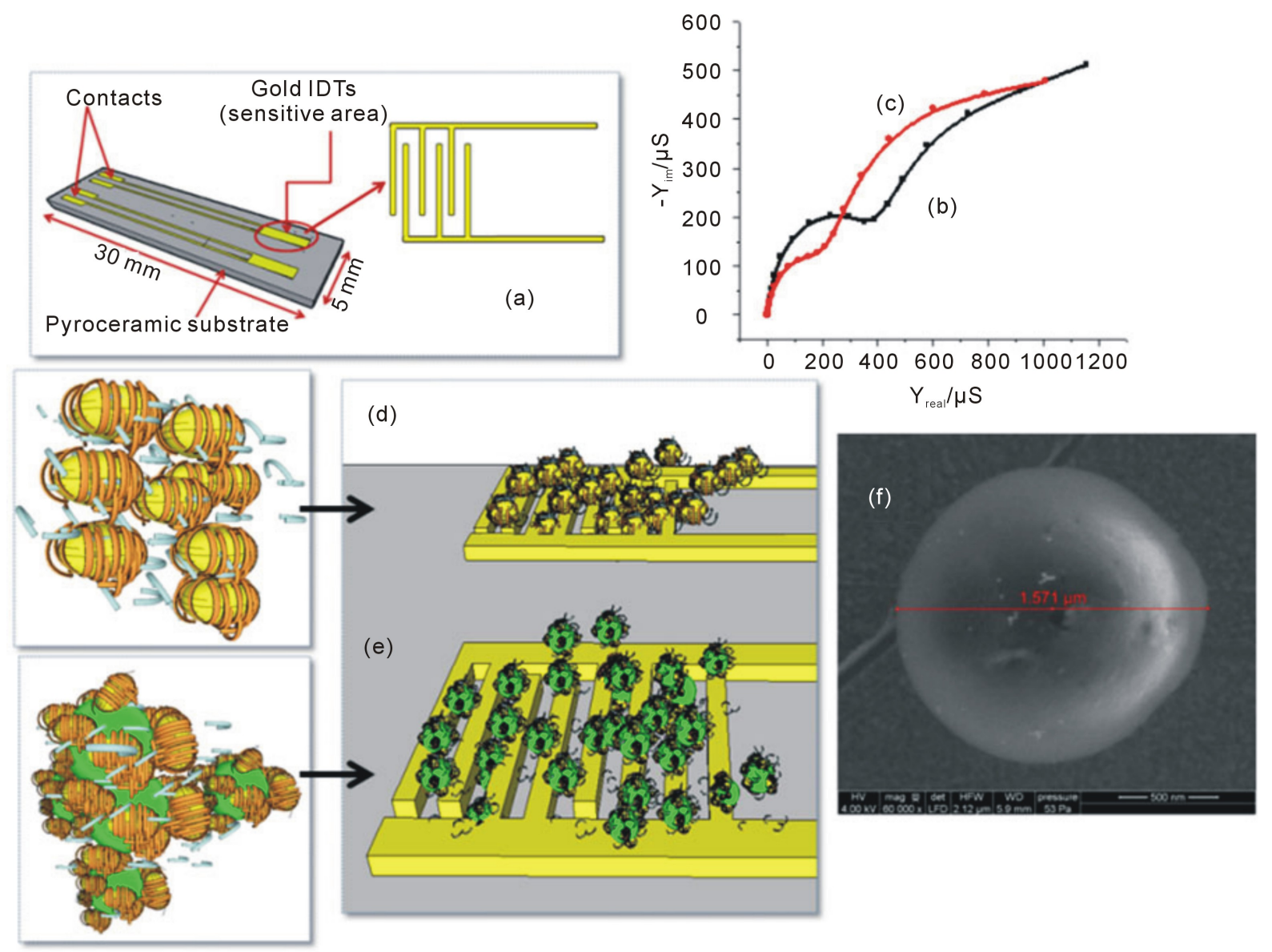

Figure 1. (a) Scheme of microelectrodes with gold IDTs [6]; (b) Complex admittance spectra of bare electrode and (c) Modified electrode, where: frequency range $=100 \mathrm{mHz}-100 \mathrm{kHz}$, amplitude potential $=10 \mathrm{mV}$, with measurements made in phosphate buffer (5 mM at pH 5.2). (d) BSA (20\%) mixed with PAH-coated gold nanoparticles, immobilized on the reference electrode, through cross-linking under glutaraldehyde vapours; (e) Spirulina cells mixed with PAH-coated gold nanoparticles and BSA (20\%), immobilized on the working electrode, through cross-linking under glutaraldehyde vapours; (f) SEM image of Spirulina cell.

Lange, France) in a two electrode configuration. Data acquisition and processing via "Voltamaster" software was provided by the same company. All EIS measurements were taken at a frequency range of $100 \mathrm{mHz}$ to 100 $\mathrm{kHz}$ at room temperature. The same glass vessel $(4 \mathrm{~mL})$ was filled with $5 \mathrm{mM}$ phosphate buffer under vigorous magnetic stirring.

\subsection{Preparation of PAH-Coated Gold Nanoparticles}

A suspension of gold nanoparticles $(1 \% \mathrm{w} / \mathrm{w})$ was firstly centrifuged at $20^{\circ} \mathrm{C}$ using a SIGMA 2 - 6 K Centrifuge from Fisher Bioblock Scientific at $9000 \mathrm{rpm}$ for $20 \mathrm{~min}$. The supernatant phase was then eliminated and the gold nanoparticles were immersed in $100 \mathrm{~mL}$ of aqueous solutions of $5 \mathrm{mg} . \mathrm{mL}^{-1}$ of PAH (positive charge), under mechanical stirring for $15 \mathrm{~min}$. After the adsorption process, PAH-coated gold nanoparticles were removed by similar centrifuging and redispersion in $20 \mathrm{mM}$ of phosphate buffer at $\mathrm{pH}$ 7.3.

\subsection{Biosensor Functionalization}

IDT electrodes were cleaned by sonication in acetone for $10 \mathrm{~min}$, followed by chemical treatment in a piranha solution $\left(\mathrm{H}_{2} \mathrm{SO}_{4} / \mathrm{H}_{2} \mathrm{O}_{2}, 3: 1 \mathrm{v} / \mathrm{v}\right)$ for $5 \mathrm{~min}$. The electrodes were then rinsed with absolute ethanol and finally dried under a flow of nitrogen.

The PAH-coated gold nanoparticles were dispersed in $20 \mathrm{mM}$ phosphate buffer ( $\mathrm{pH}$ 7.3) containing 5\% BSA 
and $5 \%$ Spirulina solution $(0.3 \mathrm{~g} / \mathrm{L})$. After 1 hour of mixing, a volume of $0.7 \mu \mathrm{L}$ of this solution was deposited onto the sensitive area of the first pair of IDTs representing the working sensor (Figure 1(e)). On the second pair of IDTs representing the reference sensor (Figure 1(d)), PAH-coated gold nanoparticles were dispersed in $20 \mathrm{mM}$ phosphate buffer (pH 7.3) containing $20 \%$ BSA and $0.7 \mu \mathrm{L}$ of this solution was deposited onto the sensitive area of the reference sensor. This configuration allowed differential mode measurements. The sensors were then placed in saturated GA vapours for $30 \mathrm{~min}$. After exposure, the biosensors were dried at room temperature for $30 \mathrm{~min}$ and stored at $4^{\circ} \mathrm{C}$ before the experiments.

\subsection{Biosensor Application to Effluent Samples}

Urban sewage and hospital effluents are managed in parallel along two separate lines. They were sampled through automated water sampling at the effluent treatment plant (ETP) entrance and effluent treatment plant output: Hospital Raw Water (HRW), Urban Raw Water (URW), Hospital Treated Water (HTW) and Urban Treated Water (UTW). Three points are tracked on the river: one point upstream of the river (UR), one point immediately downstream of the discharge from the sewage treatment plant (Downstream 1 of the River (DR1)) and one point further along (Downstream 2 of the River (DR2) (Figure 2).

\section{Results and Discussion}

\subsection{Cell Immobilization}

Electrochemical admittance spectra were recorded for a bare microelectrode (Figure 1(b)) and after 12 hours immobilization of Spirulina cells (Figure 1(c)). Spectra overlap shows an evolution of complex admittance spectra validating the immobilization process. SEM images revealed the coexistence of several populations of Spirulina cells 0.6 to $1.2 \mu \mathrm{m}$ in size. The presence of cells which are larger than the filter used could be explained by the pressure applied during filtration that could deform the cells and allow them to pass through the filter.

\subsection{Characteristics of Kinetics for Phosphatase and Esterase Activities}

The modified electrodes were tested for their sensitivity to both pNPP and AChCl substrates. The $\tau_{90 \%}$ response time for AChCl (Figure 3(c)) was 80 times faster than $\tau_{90 \%}$ recorded for the pNPP (Figure 3(a)). This may be due to the high accessibility of the phosphatase sites, compared to esterase sites. These responses include two phases: a first rapid one which corresponds to the external enzymes responses $(11 \mu S)$ and a second slower phase, corresponding to the response of internal enzymes (Figure 3(a), Figure 3(c)).

The calibration curve for each enzyme during exposure to various concentrations of pNPP and AChCl were investigated in triplicate and are depicted in Figure 4.

As shown in Figure 4, the enzymatic activities follow a classical Michaelis-Menten behavior and reach a level corresponding to enzyme saturation at concentrations greater or equal to $1.5 \mathrm{mM}$ pNPP and $3.5 \mathrm{mM} \mathrm{AChCl}$ respectively. Mean values and error bars were calculated from three measurements using different biosensors and the relative standard deviation of the sensor did not exceed $10 \%$.

Figure 4(b) presents the calibration curve of the APA with pNPP concentration recorded in Tekaya et al., 2013 [5], where the Spirulina cells where immobilized directly on electrodes (without gold nanoparticles) and the enzyme activity saturation corresponded to $9 \mu \mathrm{S}$ at $1.5 \mathrm{mM}$ pNPP. This conductivity increased 3 times when Spirulina cells were immobilized with PAH-coated gold nanoparticles (Figure 4(a)). It reaches $30 \mu \mathrm{S}$ at the same concentration of pNPP $(1.5 \mathrm{mM})$. The use of functionalized gold nanoparticles allows the amplification of the conductivity variation during enzymatic hydrolysis. The same phenomenon was observed with esterase detection from the overlay of both curves (Figure 4(d)). Therefore, due to their electrical conductivity, gold nanoparticles can behave as nanoelectrodes, as has already been shown by Nouira et al. [33] in the case of another hydrolase enzyme.

The storage stability of the Spirulina biosensor was monitored for more than 1 month. The biosensor responses as a function of a storage time are shown in Figure 5. Each point of the curve corresponded to an arithmetic average of 3 measurements with 3 different biosensors stored in dry conditions at $4{ }^{\circ} \mathrm{C}$ (each measurement corresponded to a response to $3.5 \mathrm{mM}$ of $\mathrm{AChCl}$ ). Experiments show a stability of the conductivity over 25 days. Therefore, the lifetime of the biosensor can be estimated to be more than 25 days. 


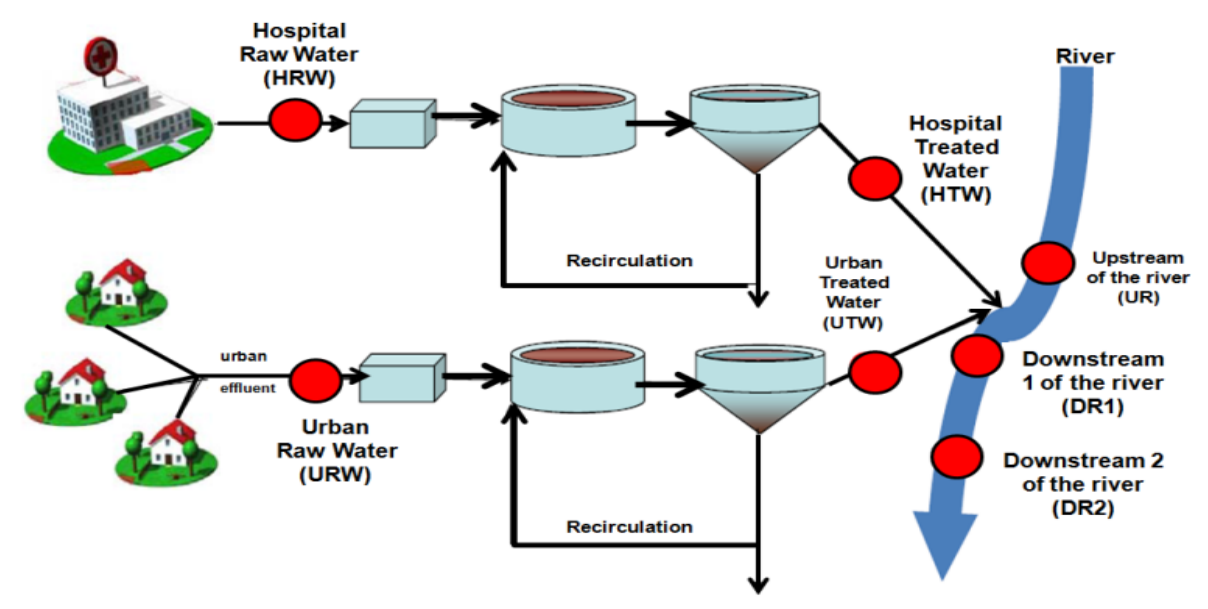

Sampling sites

Figure 2. Scheme representing the sampling sites
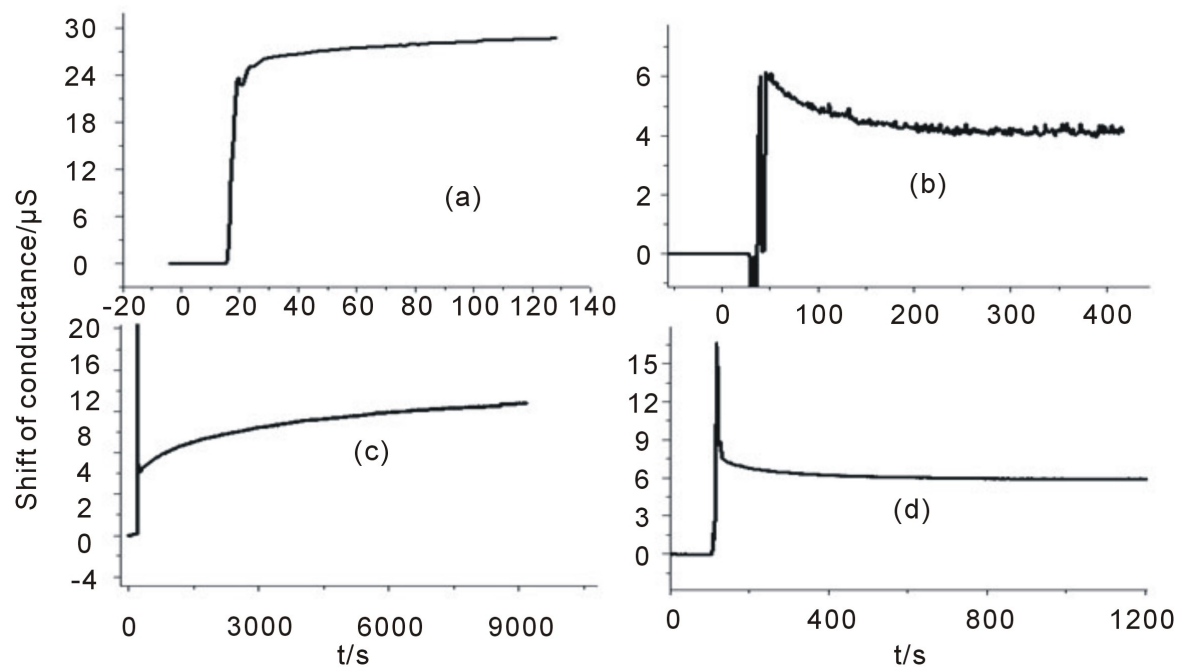

Figure 3. Typical real time response of the conductometric transducer based on Spirulina to the pNPP substrate: (a) before incubation (b) after incubation in mixture of parathion-methyl + $\mathrm{Cd}^{2+}\left(10^{-18} \mathrm{~mol} / \mathrm{L}\right)$, and to the $\mathrm{AChCl}$ substrate: (a) before incubation (b) after incubation in mixture of parathion-methyl $+\mathrm{Cd}^{2+}\left(10^{-18} \mathrm{~mol} / \mathrm{L}\right)$ for 12 hours (AChCl, $3.5 \mathrm{mM}$, pNPP, 1.5 $\mathrm{mM}$ in $5 \mathrm{mM}$ phosphate buffer at $\mathrm{pH}$ 5.2).

\subsection{Inhibition Measurements}

To evaluate the effects of pollutants on the enzymatic activity of the biosensors, measurements were performed before $\left(\mathrm{dS}_{\text {before }}\right)$ and after $\left(\mathrm{dS}_{\text {after }}\right)$ incubation in 7 concentrations of different mixtures of pesticides/metals: parathion-methyl $+\mathrm{Cd}^{2+}$, parathion-methyl $+\mathrm{Hg}^{2+}$, paraoxon-methyl $+\mathrm{Cd}^{2+}$, paraoxon-methyl $+\mathrm{Hg}^{2+}$, triazine + $\mathrm{Cd}^{2+}$ and triazine $+\mathrm{Hg}^{2+}$. This is because the detection process involves comparing enzyme activity before and after exposure to the inhibitor. The change in sensor response should therefore be attributed to the inhibitor mixture because enzyme activity is still stable and measurable after 25 days. An incubation time of 12 hours has been adopted in this study.

Results were expressed as a percentage of residual activity (Ares) (Figure 6) given by the following expression:

$$
A_{\text {res }}(\%)=\frac{\mathrm{d} S_{\text {after }}}{\mathrm{d} S_{\text {before }}} \times 100
$$



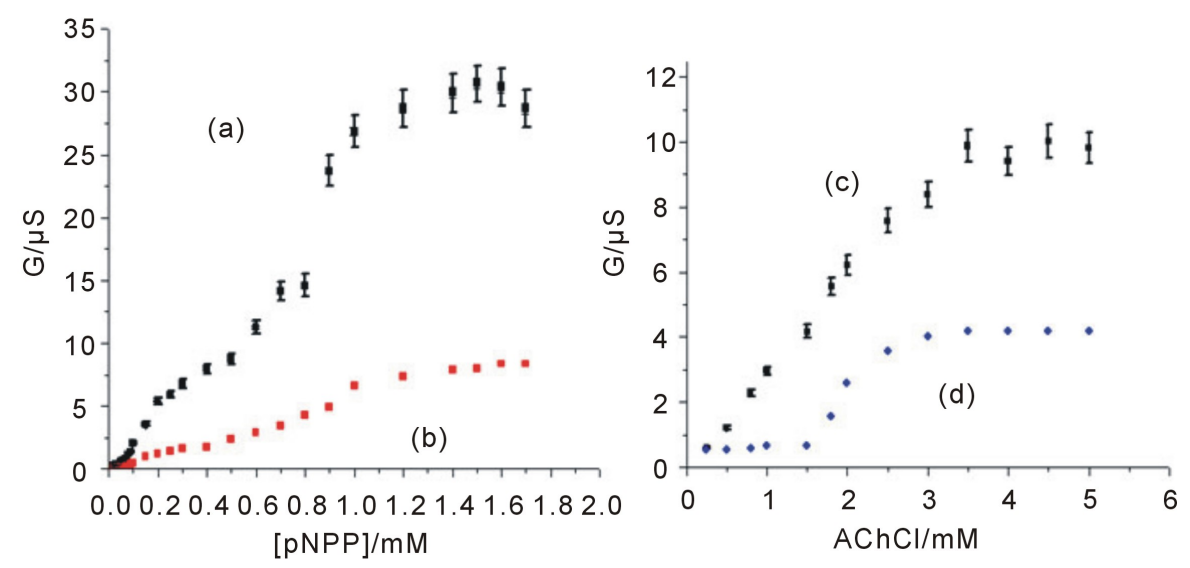

Figure 4. Calibration curve of the APA: Variation of conductance versus pNPP concentration ((a) immobilized Spirulina cells in presence of PAH-coated gold nanoparticles (b) Spirulina cells immobilized without gold nanoparticles [5] [6]. Calibration curve of the AChE: Variation of conductance versus AChCl concentration ((c) immobilized Spirulina cells in presence of PAH-coated gold nanoparticles (d) Spirulina cells immobilized without gold nanoparticles. The mean values and error bars have been calculated from 3 experiments with different biosensors, under the same experimental conditions (5 mM phosphate buffer at $\mathrm{pH}$ 5.2).

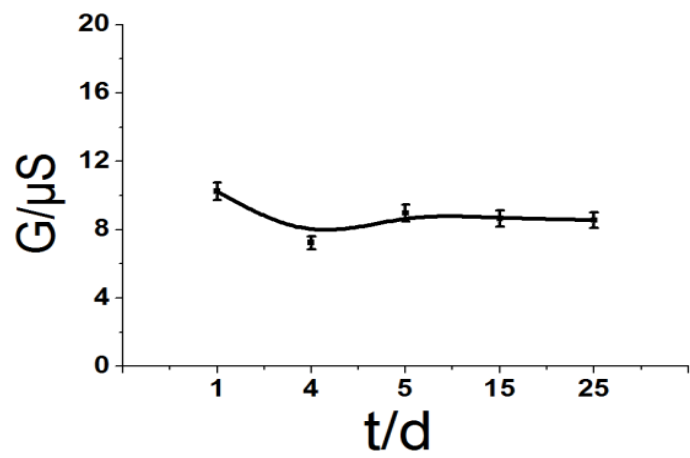

Figure 5. Evolution of the signal of conductometric biosensors stored at $4^{\circ} \mathrm{C}$ in dry conditions. The mean values and error bars have been calculated from 3 experiments with different biosensors, under the same experimental conditions ( $\mathrm{AChCl}, 3.5 \mathrm{mM}$ in $5 \mathrm{mM}$ phosphate buffer at $\mathrm{pH}$ 5.2).

Control measurements have been carried out in the same conditions. There was no inhibition phenomenon with an incubated biosensor in pesticide and tested with pNPP, also with an incubated biosensor in metallic cations and tested with AChCl. So, it can be noted that each enzyme was inhibited only by one class of inhibitor.

\subsubsection{Effect of Pollutant Mixtures on Biosensor Response Time}

Inhibition measurements and pollutants detection experiments were performed at substrates saturation concentration of $1.5 \mathrm{mM}$ pNPP and $3.5 \mathrm{mM} \mathrm{AChCl}$. The $\tau_{90 \%}$ response time to pNPP increased after incubation in a mixture of pesticide/metal. An example of a mixture of parathion-methyl $+\mathrm{Cd}^{2+}\left(10^{-18} \mathrm{~mol} / \mathrm{L}\right)$ is shown in Figure 3(b). However, with the same sensor incubated in the same mixture, a remarkable decrease in the $\tau_{90 \%}$ electrode response time to $\mathrm{AChCl}$ was revealed after incubation (Figure 3(d)).

The $\tau_{90 \%}$ response time to pNPP recorded before incubation was $12 \mathrm{sec}$ and became $8 \mathrm{~min}$ after incubation in a mixture of pesticide/metal. These response times are similar to those recorded with the same biosensor incubated in cadmium, as reported in Tekaya et al. [5].

The $\tau_{90 \%}$ response time to $\mathrm{AChCl}$ recorded before incubation in a mixture of pesticide/metal was 75 min and became 6 min after. This is also consistent with the response times recorded with a biosensor incubated with pesticides alone and reported in Tekaya et al., [6]. 

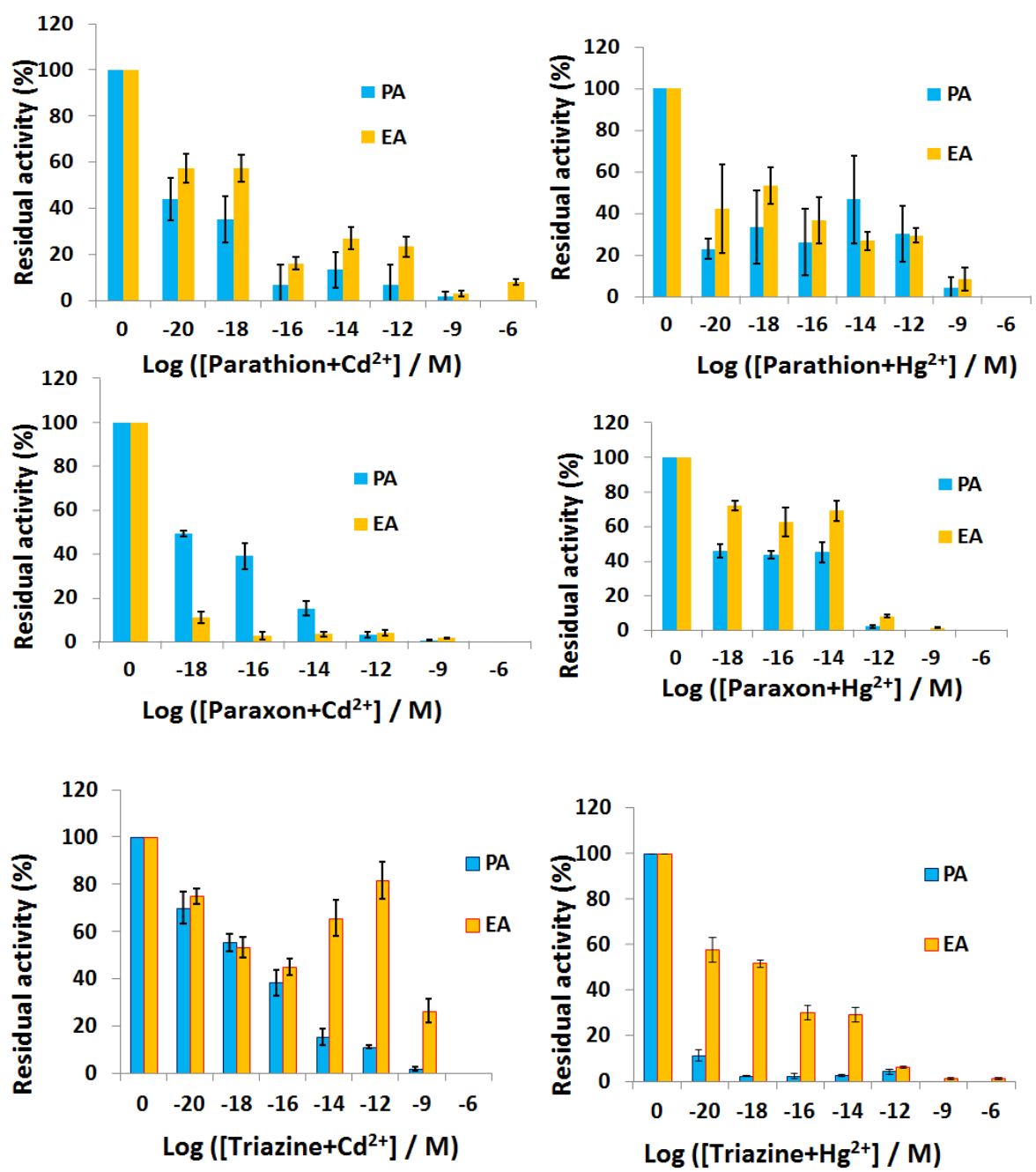

Figure 6. Phosphate ${ }_{\text {res }}$ and Esterase $\mathrm{e}_{\text {res }}$ (residual) for $12 \mathrm{~h}$ exposure to parathion-methyl $+\mathrm{Cd}^{2+}$, parathion-methyl $+\mathrm{Hg}^{2+}$, paraoxon-methyl $+\mathrm{Cd}^{2+}$ and paraoxon-methyl $+\mathrm{Hg}^{2+}$, triazine + $\mathrm{Cd}^{2+}$ and triazine $+\mathrm{Hg}^{2+}$. The mean values and error bars have been calculated from 3 experiments with different biosensors under the same experimental conditions (pNPP, 1, 5 $\mathrm{mM}, \mathrm{AChCl}, 3.5 \mathrm{mM}$, in $5 \mathrm{mM}$ phosphate buffer at $\mathrm{pH}$ 5.2).

The response in Figure 3(b) (after APA inhibition) includes two phases; the first phase is rapid and corresponds to the enzyme response. The second phase is slower and corresponds to a cell rearrangement. In fact, after APA inhibition, the presence of metallic cations prevents the substrate from reaching the phosphatase sites of Spirulina cells easily. This is due to the changes in cell morphology in the presence of heavy metals as shown in Figure 7(a), where a change of morphology occurs [5] [6]. This was the first defense mechanism against toxic trace heavy metals. SEM images do not show any modification of the cell morphology after exposure to pesticides at low concentration (Figure $7(b))$, whereas, at high concentration $\left(10^{-6} \mathrm{M}\right)$, a perforation of cell membrane is observed [6].

No antagonistic effects of the different mixtures could be observed on both enzymatic activities (Phosphatase activity is inhibited only with heavy metals and Esterase activity is inhibited only with pesticides). Besides, interactions of phosphatase with metallic cations are quite different from those of esterase with pesticides (different evolutions in response times before and after incubations in pollutants have been observed). Subsequently, this bi-enzymatic biosensor can be of great interest to discriminate toxic compounds in an unknown sample depending on the inhibited enzymatic activity. 

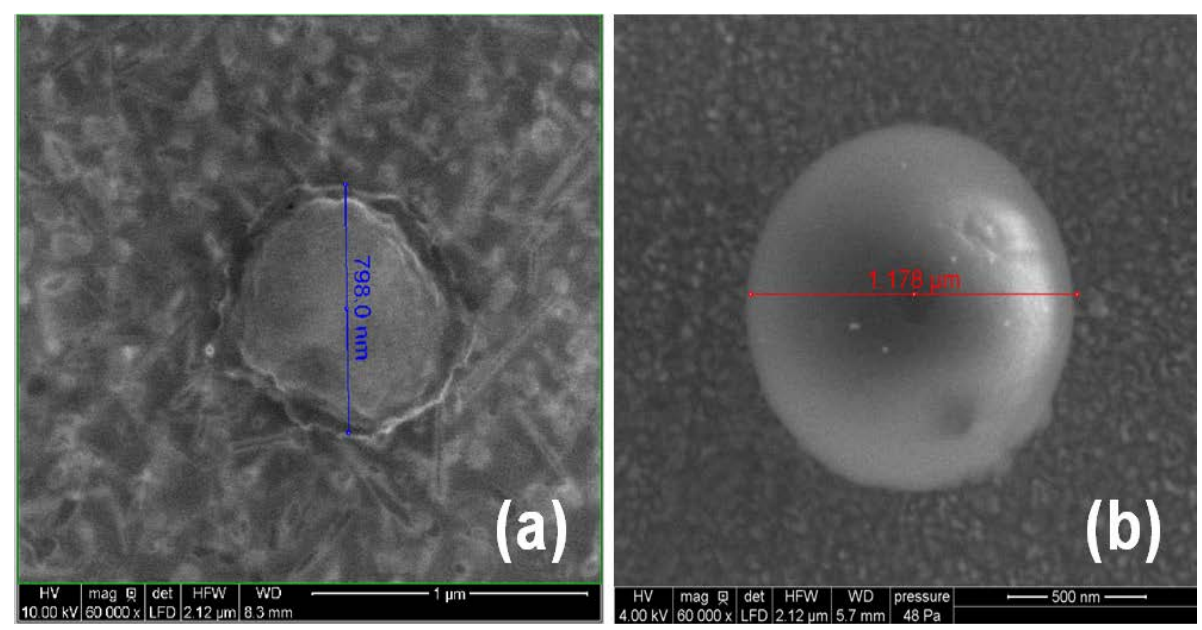

Figure 7. SEM images of Spiruina cell (a) exposed to $\mathrm{Cd}^{2+}\left(10^{-16} \mathrm{M}\right)$ (b) exposed to parathionmethyl $\left(10^{-18} \mathrm{M}\right)$.

\subsubsection{Analytical Performance for Pollutant Mixtures}

Both residual Phosphatase and Esterase activities are presented in Figure 6. Experiments were carried out after $12 \mathrm{hr}$ exposure to different mixtures of pesticide/metal with equal concentrations going from $10^{-20} \mathrm{M}$ to $10^{-06} \mathrm{M}$ (Figure 6).

These histograms show that both activities can be inhibited in the presence of parathion-methyl $+\mathrm{Cd}^{2+}$, parathion-methyl $+\mathrm{Hg}^{2+}$, paraoxon-methyl $+\mathrm{Cd}^{2+}$, paraoxon-methyl $+\mathrm{Hg}^{2+}$, triazine $+\mathrm{Cd}^{2+}$, triazine $+\mathrm{Hg}^{2+}$ (Figure 6). These observations confirm results obtained with APA measurements alone, reported in Tekaya et al., [5], and results obtained with $\mathrm{AChCl}$ measurements alone, reported in Tekaya et al., [6] and using the same microalga; Arthrospira platensis. These results are summarized in Table 1.

In this study, the quantification limits were lower in comparison with previous studies performed with conductometric biosensors based on Chlorella, with a mixture of paraoxon-methyl $+\mathrm{Cd}^{2+}[26]$. They are also low compared to acetylcholinesterase pure enzyme biosensors [21] [36] [37] and urease pure enzyme biosensors [21].

\subsection{Residual Activities in Effluent Samples}

Enzymatic activities were measured before and after incubation for 12 hours. Residual activities were calculated by providing five different micro-sensors for each sample and are presented in Figure 8. Important inhibition of enzymatic activities was revealed in samples HRW, URW, UR, DR1 and DR2 revealing the presence of toxic substances.

After the passage of the effluent throughout the treatment plant, enzyme inhibition decreases due to the effect of water treatment and residual activities (phosphatase ${ }_{\text {res }}$ and esterase $_{\text {res}}$ ) reached $100 \%$ in samples HTW and UTW (Figure 8).

Low esterase residual activity is revealed in the Hospital Raw Water (HRW) sample $(=10 \%)$; this observation could be explained by the presence of some drugs in this effluent that could inhibit esterase activity.

Upstream of urban effluent, there are areas of intensive agriculture thus marking the presence of pesticides in sample taken from URW (Figure 8).

Total AChE inhibition in samples DR1 and DR2 is due to the overfull discharged by the municipal wastewater treatment plant in the period of our sampling campaign (Figure 8).

The water samples were analyzed by ICP-MS. They show mercury concentrations relatively higher than cadmium concentrations in water samples. A high concentration of mercury was recorded in URW sample (8.9 $\mu \mathrm{g} / \mathrm{L}$ ) in good agreement with the important inhibition rate of APA recorded with the biosensor (Figure 8).

After the passage of the effluent throughout the treatment plant, mercury concentrations decreases going from 1.9 in HRW to 0.8 in HTW and from 8.9 in URW to 0.4 in UTW (Table 2). This evolution is consistent with the bi-enzymatic biosensor measurements (Figure 8). 
Table 1. Quantification limits and IC50 of each pollutant [5] [6] and of each mixture of pollutants.

\begin{tabular}{|c|c|c|}
\hline Polluant & Quantification Limit & IC50 \\
\hline $\mathrm{Cd}^{2+}$ & Pure solution of pollutant $10^{-20} \mathrm{M}$ & $10^{-18} \mathrm{M}$ \\
\hline $\mathrm{Hg}^{2+}$ & $10^{-20} \mathrm{M}$ & $10^{-16} \mathrm{M}$ \\
\hline Parathion-methyl & $10^{-20} \mathrm{M}$ & $10^{-16} \mathrm{M}$ \\
\hline Paraoxon-methyl & $10^{-18} \mathrm{M}$ & $10^{-16} \mathrm{M}$ \\
\hline \multirow[t]{2}{*}{ Triazine } & $10^{-20} \mathrm{M}$ & $10^{-18} \mathrm{M}$ \\
\hline & Mixture of Parathion-methyl $+\mathrm{Cd}^{2+}$ & \\
\hline Parathion-methyl & $10^{-20} \mathrm{M}$ & $10^{-16} \mathrm{M}$ \\
\hline \multirow[t]{2}{*}{$\mathrm{Cd}^{2+}$} & $10^{-20} \mathrm{M}$ & $10^{-16} \mathrm{M}$ \\
\hline & Mixture of Parathion-methyl $+\mathrm{Hg}^{2+}$ & \\
\hline Parathion-methyl & $10^{-20} \mathrm{M}$ & $10^{-16} \mathrm{M}$ \\
\hline \multirow[t]{2}{*}{$\mathrm{Hg}^{2+}$} & $10^{-20} \mathrm{M}$ & $10^{-16} \mathrm{M}$ \\
\hline & Mixture of Paraoxon-methyl $+\mathrm{Cd}^{2+}$ & \\
\hline \multirow[t]{2}{*}{ Paraoxon-methyl } & $10^{-18} \mathrm{M}$ & $10^{-16} \mathrm{M}$ \\
\hline & Mixture of Paraoxon-methyl $+\mathrm{Hg}^{2+}$ & \\
\hline \multirow[t]{2}{*}{ Paraoxon-methyl } & $10^{-18} \mathrm{M}$ & $10^{-16} \mathrm{M}$ \\
\hline & Mixture of Triazine $+\mathrm{Cd}^{2+}$ & \\
\hline Triazine & $10^{-20} \mathrm{M}$ & $10^{-16} \mathrm{M}$ \\
\hline \multirow[t]{2}{*}{$\mathrm{Cd}^{2+}$} & $10^{-20} \mathrm{M}$ & $10^{-16} \mathrm{M}$ \\
\hline & Mixture of Triazine $+\mathrm{Hg}^{2+}$ & \\
\hline Triazine & $10^{-20} \mathrm{M}$ & $10^{-16} \mathrm{M}$ \\
\hline
\end{tabular}

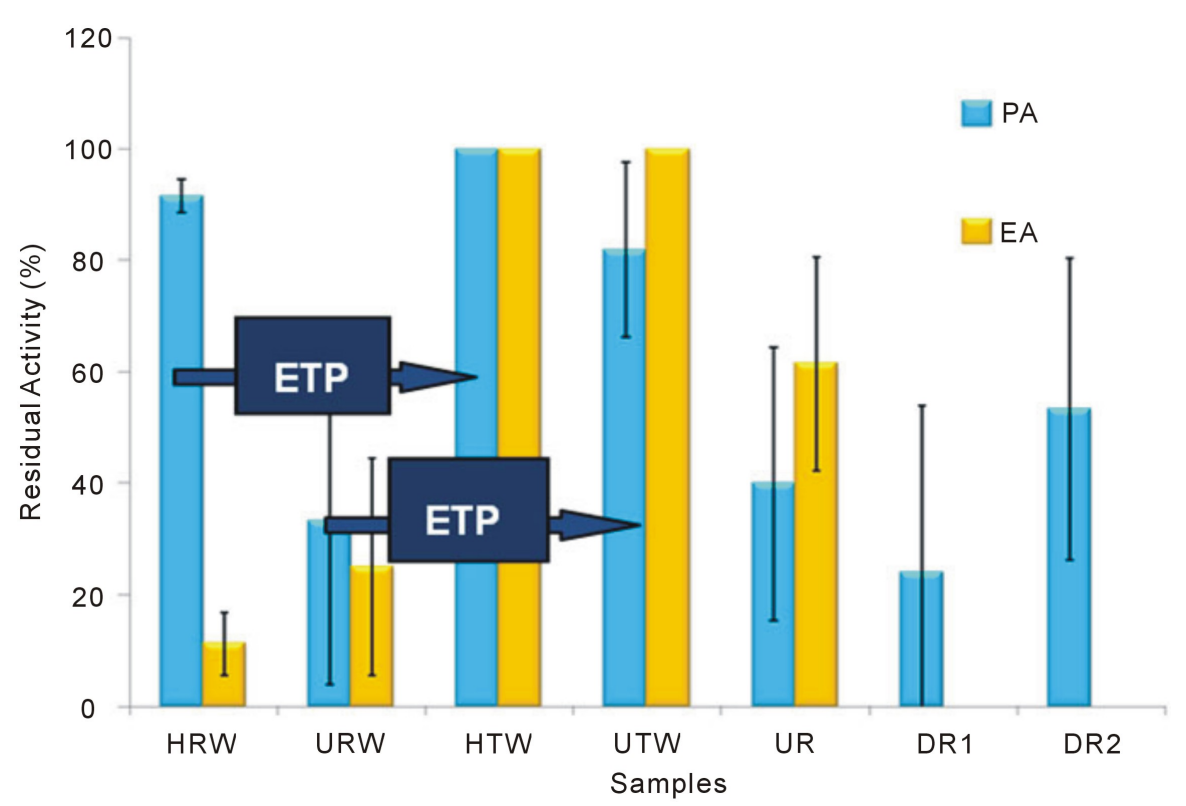

Figure 8. Phosphatase $\mathrm{res}_{\text {res }}$ and Esterase es $_{\text {res }}$ (residual) for $12 \mathrm{~h}$ incubation in samples, The mean values and error bars have been calculated from 5 experiments with different biosensors under the same experimental conditions (pNPP, $1.5 \mathrm{mM}$, AChCl, $3.5 \mathrm{mM}$, in $5 \mathrm{mM}$ phosphate buffer at $\mathrm{pH}$ 5.2).

\section{Conclusion}

In this work, it is possible to elaborate a bi-enzymatic biosensor with only one bioreceptor based on the inhibition of enzyme activities by toxic compounds. It has been demonstrated for heavy metal ions that the inhibition rates are in a close correlation with the mercury content in the real water sample. The developed biosensor is 
Table 2. Heavy metals concentrations determined with ICP-MS methods.

\begin{tabular}{ccc}
\hline Sample & $\mathbf{C d}(\boldsymbol{\mu g} / \mathbf{L})$ & $\mathbf{H g}(\boldsymbol{\mu g} / \mathbf{L})$ \\
UR & $<0.2$ & $<0.4$ \\
DR1 & $<0.2$ & 2.2 \\
DR2 & $<0.2$ & 1.0 \\
HRW dissolved & $<0.2$ & 1.9 \\
HRW particulate & $<0.2$ & 2.6 \\
HTW & $<0.2$ & 0.8 \\
URW dissolved & $<0.2$ & 0.5 \\
URW particulate & $<0.2$ & 8.9 \\
UTW & $<0.2$ & $<0.4$ \\
\hline
\end{tabular}

simple and cheap, compared to classical analytical methods and it can provide a rapid scanning of the environment, as an early-warning system.

\section{Acknowledgements}

The authors would like to thank CAMPUS-FRANCE for their financial support through PHC Maghreb Project No. 12 MAG 088 and UTIQUE Project No. 13G 1205. The authors thank SIPIBEL program for providing water samples.

\section{References}

[1] Kamanyire, R. and Karalliedde, L. (2004) Organophosphate Toxicity and Occupational Exposure. Occupational Medicine, 54, 69-75. http://dx.doi.org/10.1093/occmed/kqh018

[2] Alavanja, M.C.R., Dosemeci, M., Samanic, C., Lubin, J., Lynch, CF., Knott, C., et al. (2004) Pesticides and Lung Cancer Risk in the Agricultural Health Study Cohort. American Journal of Epidemiology, 160, 876-885. http://dx.doi.org/10.1093/aje/kwh290

[3] Sbartai, A., Namour, P., Errachid, A., Krejci, J., Sejnohova, R., Renaud, L., Hamlaoui, M.L., Loir, A.S., Garrelie, F., Donnet, C., Soder, H., Audouard, E., Granier, J. and Jaffrezic-Renault, N. (2012) Electrochemical Boron-Doped Diamond Film Microcells Micromachined with Femtosecond Laser: Application to the Determination of Water Framework Directive Metals. Analytical Chemistry, 84, 4805-4811. http://dx.doi.org/10.1021/ac3003598

[4] Dennison, M.J. and Turner, A.P.F. (1995) Biosensors for Environmental Monitoring. Journal of Biotechnology, Adv. 13, 1.

[5] Tekaya, N., Saiapina, O., Ben Ouada, H., Lagarde, F., Ben Ouada, H. and Jaffrezic-Renault, N. (2013) Ultra-Sensitive Conductometric Detection of Heavy Metals Based on Inhibition of Alkaline Phosphatase Activity from Arthrospira platensis. Journal of Bioelectrochemistry, 90, 24-29. http://dx.doi.org/10.1016/j.bioelechem.2012.10.001

[6] Tekaya, N., Saiapina, O., Ben Ouada, H., Lagarde, F., Ben Ouada, H. and Jaffrezic-Renault, N. (2013) Ultra-Sensitive Conductometric Detection of Pesticides Based on Inhibition of Esterase Activity in Arthrospira platensis. Environmental Pollution, 178, 182-188. http://dx.doi.org/10.1016/j.envpol.2013.03.013

[7] Tekaya, N., Gammoudi, I., Braiek, M., Tarbague, H., Moroté, F., Raimbault, V., Sakly, N., Rebière, D., Ben Ouada, H., Lagarde, F., Ben Ouada, H., Cohen-Bouhacina, T., Dejous, C. and Jaffrezic Renault, N. (2013) Acoustic, Electrochemical and Microscopic Characterization of Interaction of Arthrospira platensis Biofilm and Heavy Metal Ions. Journal of Environmental Chemical Engineering, 1, 609-619. http://dx.doi.org/10.1016/j.jece.2013.07.006

[8] Tekaya, N., Sakly, N., Ben Ouada, H., Ben Ouada, H., Jaffrezic-Renault, N. and Lagarde, F. (2011) Impedimetric Characterization of Alginate Entrapped Arthrospira platensis at a Platinum/Electrolyte Interface. Effect of Cadmium Ions. Sensor Letters, 9, 1-5.

[9] Halamek, J., Pribyl, J., Makower, A., Skladal, P. and Scheller, F.W. (2005) Sensitive Detection of Organophosphates in River Water by Means of a Piezoelectric Biosensor. Analytical and Bioanalytical Chemistry, 382, 1904-1911. http://dx.doi.org/10.1007/s00216-005-3260-y

[10] Marty, J.L., Garcia, D. and Rouillon, R. (1995) Biosensor: Potential in Pesticide Detection. Trends in Analytical Chemistry, 14, 329-333.

[11] La Rosa, C., Pariente, F., Hernandez, L. and Lorenzo, E. (1995) Amperometric Flow-Through Biosensor from the Determination of Pesticides. Analytica Chimica Acta, 308, 129-136. http://dx.doi.org/10.1016/0003-2670(94)00529-U 
[12] Campanella, L., Achilli, M., Sammartino, M.P. and Tomassetti, M. (1991) Butyrylcholine Enzyme Sensor for Determining Organophosphorus Inhibitors. Bioelectrochemistry and Bioenergetics, 26, 237. http://dx.doi.org/10.1016/0302-4598(91)80027-Z

[13] Martorell, D., Cespedes, F., Martinez-Fabregas, E. and Alegret, S. (1994) Amperometric Determination of Pesticides Using Biosensor Based on Polishable Graphite-Epoxy Biocomposit. Analytica Chimica Acta, 290, 343-348. http://dx.doi.org/10.1016/0003-2670(94)80121-5

[14] Gogol, E.V., Evtugyn, G.A, Marty, J.L, Budnikov, H.C and Winter, V.G. (2000) Amperometric Biosensors Based on Nafion Coated Screen-Printed Electrodes for the Determination of Cholinesterase Inhibitors. Talanta, 53, 379-389. http://dx.doi.org/10.1016/S0039-9140(00)00507-5

[15] Mulchandani, A., Chen, W., Mulchandani, P., Wang, J. and Rogers, K.R. (2001) Biosensors for Direct Determination of Organophosphate Pesticides. Biosensors and Bioelectronics, 16, 225-230. http://dx.doi.org/10.1016/S0956-5663(01)00126-9

[16] Marty, J.L., Mionetto, N., Noguer, T., Ortega, T. and Roux, C. (1993) Enzyme Sensors for the Detection of Pesticides. Biosensors and Bioelectronics, 8, 273-280. http://dx.doi.org/10.1016/0956-5663(93)85007-B

[17] Bernabei, M., Cremisini, C., Mascini, M. and Palleschi, G. (1991) Determination of Organophophorus and Carbamic Pesticides with a Choline and Acetylcholine Electrochemical Biosensor. Analytical Letters, 24, 1317-1331. http://dx.doi.org/10.1080/00032719108052974

[18] Dzyadevych, S.V., Shulga, A.A., Soldalkin, A.P., Hendji, A.M.N., Jaffrezic-Renault, N. and Martelet, C. (1994) Conductometric Biosensors Based on Cholinesterases for Sensitive Detection of Pesticides. Electroanalysis, 6, 752-758. http://dx.doi.org/10.1002/elan.1140060907

[19] Rekha, K., Thakur, M.S. and Karanth, N.G. (2000) Biosensors for Detection of Organophosphorous Pesticides. Critical Reviews in Biotechnology, 20, 213-235. http://dx.doi.org/10.1080/07388550008984170

[20] Zhylyak, G.A., Dzyadevych, S.V., Korpan, Y.I., Soldatkin, A.P. and El’Skaya, A.V. (1995) Application of Urease Conductometric Biosensor for Heavy Metal Ion Determination. Sensors and Actuators B: Chemical, 24, 145-148.

[21] Arkhypova, V.N., Dzyadevych, S.V., Soldatkin, A.P., El’skaya, A.V., Jaffrezic-Renault, N., Jaffrezic, H. and Martelet, C. (2001) Multibiosensor Based on Enzyme Inhibition Analysis for Determination of Different Toxic Substances. Talanta, 55, 919-927. http://dx.doi.org/10.1016/S0039-9140(01)00495-7

[22] Jaffrezic-Renault, N. and Dzyadevych, S.V. (2008) Conductometric Microbiosensors for Environmental Monitoring. Sensors, 8, 2569-2588. http://dx.doi.org/10.3390/s8042569

[23] Berezhetskyy, L., Durrieu, C., Nguyen-Ngoc, H., Chovelon, J.M., Dzyadevych, S.V. and Tran-Minh, C. (2007) Development of Conductometric Biosensors Based on Alkaline Phosphatases for the Water Quality Control. Biopolymers and Cell, 23, 511-518.

[24] Durrieu, C. and Tran-Minh, C. (2002) Optical Algal Biosensor Using Alkaline Phosphatase for Determination of Heavy Metals. Ecotoxicology and Environmental Safety, 51, 206-209. http://dx.doi.org/10.1006/eesa.2001.2140

[25] Pandard, P., Vasseur, P. and Rawson, D.M. (1993) Comparison of Two Types of Sensors Using Eukaryotic Algae to Monitor Pollution of Aquatic Systems. Water Research, 27, 427-431. http://dx.doi.org/10.1016/0043-1354(93)90043-H

[26] Chouteau, C., Dzyadevych, S., Durrieu, C. and Chovelon, J.M. (2005) A Bi-Enzymatic Whole Cell Conductometric Biosensor for Heavy Metal Ions and Pesticides Detection in Water Samples. Biosensors and Bioelectronics, 21, 273-281. http://dx.doi.org/10.1016/j.bios.2004.09.032

[27] Guedri, H. and Durrieu, C. (2008) A Self-Assembled Monolayers Based Conductometric Algal Whole Cell Biosensor for Water Monitoring. Microchimica Acta, 163, 179-184. http://dx.doi.org/10.1007/s00604-008-0017-2

[28] Tekaya, N., Tarbague, H., Moroté, F., Gammoudi, I., Sakly, N., Ben Ouada, H., Raimbault, V., Rebière, D., Ben Ouada, H., Jaffrezic-Renault, N., Lagarde, F., Dejous, C. and Cohen-Bouhacina, T. (2012) Optimization of Spirulina Biofilm for in-Situ Heavy Metals Detection with Microfluidic-Acoustic Sensor and AFM. Proceedings of Meeting on Chemical Sensors (IMCS), Nuremburg, 20-23 May 2012, 92-95.

[29] Salvi, S., Trinei, M., Lanfaloni, L. and Pon, C.L. (1994) Cloning and Characterization of the Gene Encoding an Esterase from Spirulina platensis. Molecular and General Genetics, 243, 124-126. http://dx.doi.org/10.1007/BF00283885

[30] Luo, H., Benner, R., Long, R.A. and Hu, J. (2009) Subcellular Localization of Marine Bacterial Alkaline Phosphatases. Proceedings of the National Academy of Sciences of the United States of America, 106, 21219-21223. http://dx.doi.org/10.1073/pnas.0907586106

[31] Dzyadevych, S.V., Arkhypova, V.N., Korpan, Y.I., El’skaya, A.V., Soldatkin, A.P., Jaffrezic-Renault, N. and Martelet, C. (2001) Conductometric Formaldehyde Sensitive Biosensor with Specifically Adapted Analytical Characteristics. Analytica Chimica Acta, 445, 47-55. http://dx.doi.org/10.1016/S0003-2670(01)01249-1 
[32] Anh, T.M., Dzyadevych, S.V., Van, M.C., Jaffrezic Renault, N., Duc, C.N. and Chovelon, J.M. (2004) Conductometric Tyrosinase Biosensor for the Detection of Diuron, Atrazine and Its Main Metabolites. Talanta, 63, 365-370. http://dx.doi.org/10.1016/j.talanta.2003.11.008

[33] Nouira, W., Maaref, A., Vocanson, F., Siadat, M., Saulnier, J., Lagarde, F. and Jaffrezic-Renault, N. (2012) Enhancement of Enzymatic IDE Biosensor Response Using Gold Nanoparticles. Exemple of the Detection of Urea. Electroanalysis, 24, 1088-1094. http://dx.doi.org/10.1002/elan.201100681

[34] Arkhypova, V.M., Bereghetskyy, A.L., Shulga, O.A., Chovelon, J.M., Soldatkin, O.P. and Dzyadevych, S.V. (2005) Investigation and Optimization of Conductometric Transducers Based on Planar Technology. Sensor Electronics and Microsystem Technologies, 2, 48-54.

[35] Dzyadevych, S.V., Soldatkin, A.P., Soldatkin, A.A., Peshkova, V.N., Vasilenko, A.D., Melnik, V.G., Mikhal, A.A., Semenycheva, L.N. and Rubanchuk, M.P. (2009) Four-Channel Biosensor's Analyser of Saccharides. Sensor Electronics and Microsystem Technologies, 3, 47-53.

[36] Dzyadevych, S.V., Soldatkin, A.P. and Chovelon, J.M. (2002) Assessment of the Toxicity of Methyl Parathion and Its Photodegradation Products in Water Samples Using Conductometric Enzyme Biosensors. Analytica Chimica Acta, 459, 33-41. http://dx.doi.org/10.1016/S0003-2670(02)00083-1

[37] Villatte, F., Marcel, V., Estrada-Mondaca, S. and Fournier, D. (1998) Engineering Sensitive Acetylcholinesterase for Detection of Organophosphate and Carbamate Insecticides. Biosensors and Bioelectronics, 13, 157-164. http://dx.doi.org/10.1016/S0956-5663(97)00108-5 